\title{
Atrial Natriuretic Peptide Levels Reflect Hemodynamic Changes Under Pacemaker Stimulation
}

\author{
BERND NOLL, JOACHIM KRAPPE, BURKHARD GÖKE,* \\ and BERNHARD MAISCH \\ From the Department of Internal Medicine, University of Marburg, Federal Republic of \\ Germany; and *Department of Physiology, University of Michigan, \\ Medical School, Ann Arbor, Michigan
}

NOLL, B., ET AL.: Atrial Natriuretic Peptide Levels Reflect Hemodynamic Changes Under Pacemaker Stimulation. Pacemaker stimulation influences plasma levels of atrial natriuretic peptide (ANP). This study evaluated in individuals without impaired myocardial function whether a consecutive increase of pacing rates results in reduced alteration of plasma ANP levels mirroring a putative decrease of atrial contribution to cardiac output. In nine resting patients with DDD pacemakers, absolute and relative ANP plasma levels were determined under DDD (175 msec AV delay) and VVI pacing at a pacing rate of 72, 82, 92 , and 113 beats/min. When pacing rates were consecutively increased, higher plasma ANP concentrations were measured. However, the differences in relative ANP levels between DDD and VVI pacing decreased. At 113 beats/min, both relative and absolute ANP levels were nearly identical. Therefore, it seems likely that the atrial contribution to cardiac output at high pacing rates is less important than at lower frequencies, at least when the overall myocardial function is not impaired. (PACE, Vol. 13, August 1990)

atrial natriuretic peptide, artificial pacemaker stimulation, hemodynamics

\section{Introduction}

The atrial natriuretic peptide (ANP) is intimately involved in the regulation of renal and cardiovascular homeostasis. ${ }^{1,2}$ This hormone, which is synthesized and stored predominantly in atrial myoendocrine cells, is capable of exerting potent, selective, and transient effects on fluid and electrolyte balance as well as on blood pressure. ${ }^{1,2}$ Increases of ANP plasma levels can be elicited by atrial stretch caused by volume expansion, elevation of atrial pressure, and atrial tachycardia. ${ }^{1,3,4}$

Pacemaker stimulation influences peripheral levels of atrial natriuretic peptide. ${ }^{5,6}$ Evidently,

Supported by grant no. RWH-493/51 from Stiftung P.E. Kempkes, Marburg, FRG.

Address for reprints: Bernd Noll, M.D., Dept. of Internal Medicine, University of Marburg, Baldingerstr. 1, 3550 Marburg, Federal Republic of Germany.

Received January 26, 1990; revision April 17, 1990; accepted May 7, 1990. hemodynamically beneficial pacing modes, such as AAI or DDD mode, lead to lower ANP plasma levels compared to VVI mode. ${ }^{6}$

The aim of the present study was to investigate in patients without impaired myocardial function whether dual chamber pacing at higher rates leads to less pronounced regulation in ANP plasma levels compared to the VVI mode. ${ }^{7-9}$ This is of special interest, since accumulating evidence demonstrates that ANP plasma concentrations obviously mirror the actual hemodynamic consequences of different pacing modes at various pacing rates.

\section{Methods}

Nine patients with DDD pacemakers (six with Intermedics Cosmos [Intermedics, Inc., Freeport, TX, USA], three with Biotronic Diplos 04/05 [Biotronic, Lake Oswego, OR, USA]) were examined between 8 and 11 a.m. Their mean age was 73 years. None of them showed clinical evidence 
of valvular heart disease or congestive heart failure. The respective indications for pacemaker therapy had been documented in three patients as second-or third-degree AV block and in six patients as AV block in addition to sinuatrial block ("binodal disease").

Each pacemaker was programmed to DDD mode (175 msec AV delay) and VVI mode. Furthermore, different pacing rates $(72,82,92,113$ beats/min) were chosen. At DDD mode, stimulation of both atrium and ventricle was performed exclusively by the pacemakers at all pacing rates. The patients were studied under strict resting conditions to exclude overlapping effects unrelated to those induced by the different pacing modes.

Blood was drawn from an antecubital vein 10 minutes after changing of pacing mode or rate. The time setting was chosen since ANP was shown to have a half-life of 3 minutes in blood. ${ }^{1}$

Plasma ANP was measured as previously described. ${ }^{10}$ In brief, blood samples were collected on ice into EDTA tubes containing $500 \mathrm{kU} / \mathrm{mL}$ of the protease inhibitor aprotinin (Trasylol, Bayer AG, Leverkusen, FRG). After centrifugation at $2,000 \mathrm{~g}$ at $4^{\circ} \mathrm{C}$ for 30 minutes, ANP was extracted using C18-Sep-pak cartridges (Waters Associates, Milford, MA, USA). Eluates were stored at $-70^{\circ} \mathrm{C}$ until assay. ANP was measured using a specific radioimmunoassay method (Amersham, human $\alpha$ ANP [I 125] radioimmunoassay system, code RPA.512).
Results are given as absolute ANP plasma levels during the respective pacing modes or rates. Relative changes in ANP concentration were calculated in comparison to lowest levels at each pacing rate which were assumed to be $=1$.

Statistical analysis was performed using oneway analysis of variance. Differences at the 95\% level were considered significant. All values are means \pm standard deviation (SD).

\section{Results}

Table I summarizes the results of ANP determinations in nine patients during DDD and VVI pacing at $72,82,92$, and 113 beats $/ \mathrm{min}$.

The means of the hormone levels at the respective pacing modes and rates are shown in Figure 1. At 72,82 , and 92 beats/min, ANP plasma levels were elevated during VVI pacing compared to DDD pacing, whereas the hormone levels were nearly identical at 113 beats/min pacing rate. Increasing stimulation frequency led to higher plasma concentrations of atrial natriuretic peptide.

The relative changes of ANP levels during the two different pacing modes at the respective pacing rates are shown in figure 2. During VVI pacing the relative ANP plasma levels at 72, 82, and 92 beats $/ \mathrm{min}$ pacing rate were elevated in comparison to those under dual chamber pacing. These differences were statistically significant (P $<0.05)$. Whereas the relative ANP plasma con-

Table I.

Plasma Levels of Atrial Natriuretic Peptide in Nine Patients at Different Pacing Modes and Rates

\begin{tabular}{|c|c|c|c|c|c|c|}
\hline \multirow[b]{2}{*}{ Patient } & \multirow[b]{2}{*}{ Age } & \multirow[b]{2}{*}{ Sex } & \multicolumn{4}{|c|}{ ANP Plasma Levels [fmol/ml] } \\
\hline & & & $\begin{array}{c}72 \\
\text { DDD/VVI }\end{array}$ & $\begin{array}{c}82 \\
\text { DDD/VVI }\end{array}$ & $\begin{array}{c}92 \\
\mathrm{DDD} / \mathrm{VVI}\end{array}$ & $\begin{array}{l}113 \text { bpm } \\
\text { DDD/VVI }\end{array}$ \\
\hline $\operatorname{Sch} \mathrm{J}$ & 69 & $\mathrm{~m}$ & $2.15 / 2.76$ & $3.40 / 3.58$ & $4.06 / 4.06$ & $5.63 / 5.26$ \\
\hline FK & 77 & $\mathrm{~m}$ & $15.50 / 9.91$ & $15.86 / 9.56$ & $20.74 / 21.40$ & $20.12 / 26.41$ \\
\hline $\mathrm{RM}$ & 60 & $f$ & $1.47 / 7.76$ & $5.58 / 24.87$ & $11.17 / 24.13$ & $24.06 / 20.78$ \\
\hline WW & 78 & $\mathrm{~m}$ & $7.96 / 13.58$ & $17.96 / 23.12$ & $27.04 / 27.56$ & $33.68 / 28.92$ \\
\hline Sch H & 72 & $\mathrm{~m}$ & $3.98 / 8.37$ & $6.03 / 14.06$ & $8.74 / 9.68$ & $6.94 / 13.97$ \\
\hline $\mathrm{BH}$ & 80 & $f$ & $5.29 / 7.25$ & $11.21 / 13.66$ & $15.68 / 19.84$ & $20.74 / 21.18$ \\
\hline Sch K & 79 & $f$ & $2.03 / 3.83$ & $3.12 / 4.79$ & $5.60 / 9.39$ & $14.72 / 13.53$ \\
\hline Sch E & 65 & $f$ & $3.04 / 3.82$ & $3.47 / 5.70$ & $6.10 / 7.88$ & $8.62 / 8.98$ \\
\hline MK & 77 & $f$ & $6.88 / 21.63$ & $7.51 / 25.44$ & $28.15 / 30.66$ & $34.58 / 29.03$ \\
\hline
\end{tabular}




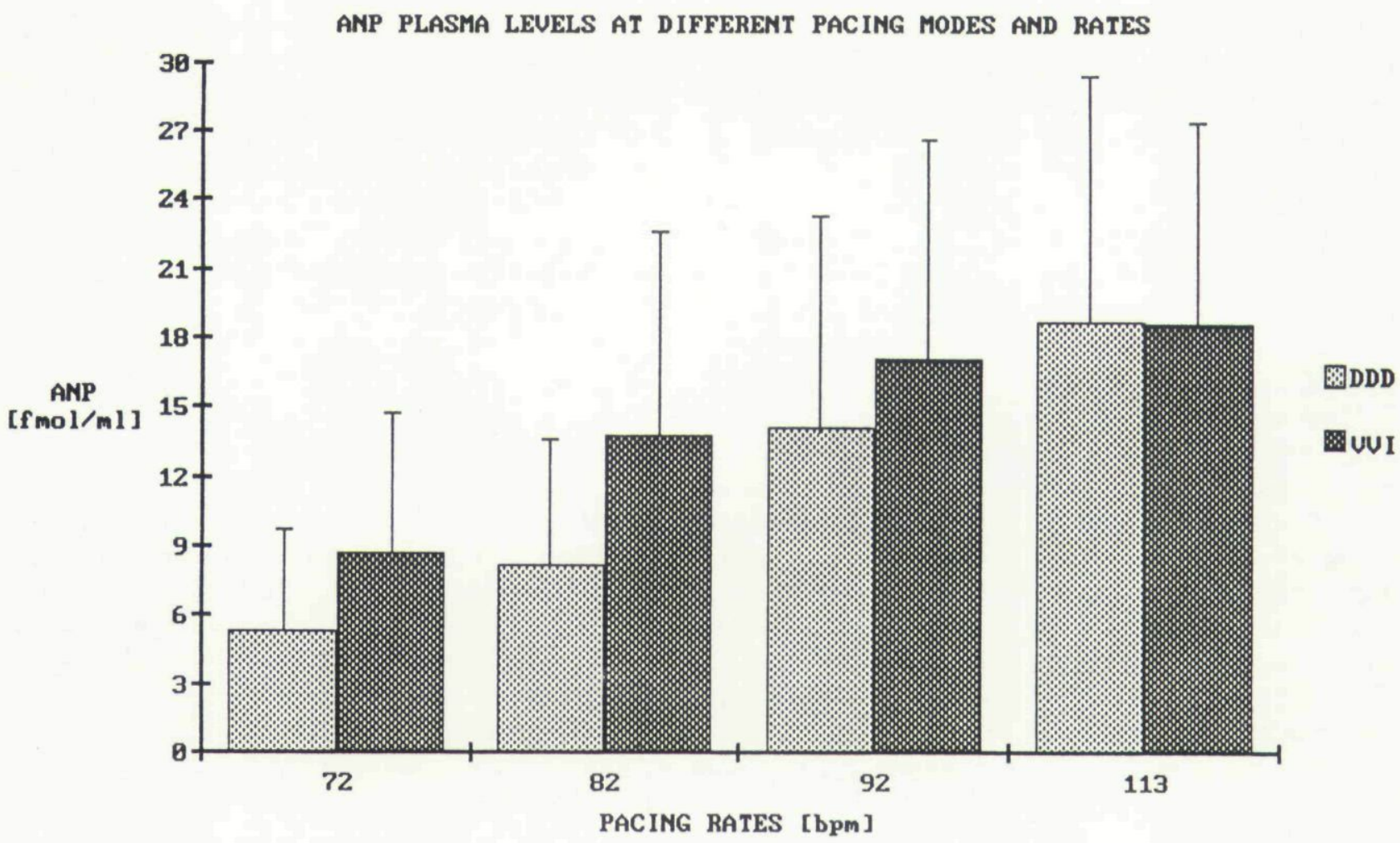

Figure 1. Mean absolute ANP plasma levels during DDD and VVI pacing at 72, 82, 92, and 113 beats/min (given are means $\pm \mathrm{SD}$ ).

centrations were twofold higher at 72 and 82 beats/min in VVI compared to DDD pacing, the differences between the two pacemaker stimulation modes at 92 beats $/ \mathrm{min}$ were less pronounced and differed only by a factor of 1.3. Finally, the relative hormone concentrations under DDD and VVl pacing at 113 beats/min were nearly identical. These data reveal decreasing differences in plasma levels of atrial natriuretic peptide between DDD and VVI pacemaker stimulation at increasing pacing rates.

\section{Discussion}

Myoendocrine cardiocytes of mammalian cardiac atria synthesize and store the ANP, a hormone with a variety of potent effects such as increase of sodium and water excretion, decrease of systemic or pulmonary vascular resistance, and suppression of plasma renin, aldosterone, and vasopressin. . $^{1,2,11,12}$

Recent reports demonstrated that pacemaker stimulation influences ANP release depending on pacing mode and pacing rate. ${ }^{4-6,13}$ The main stimulus for ANP release in cardiac pacing seems to be an increase of atrial transmural pressure and stretch. Ellenbogen and co-workers showed increases in ANP levels during sustained ventricular tachycardia ${ }^{14}$ as well as in atrial pacing at higher rates. ${ }^{15}$ Haufe et al. found that right ventricular pacing led to a pacing rate dependent increase of ANP plasma levels up to $300 \%$, whereas significantly higher hormone levels under AAI pacing occurred only at pacing rates higher than 140 beats $/ \min ^{4}{ }^{4}$ We previously demonstrated that variations of AV delay also alter peripheral ANP plasma levels. ${ }^{6}$ However, an independent effect of atrial pacing frequency on plasma concentrations of atrial natriuretic peptide in humans could not be identified.

Studies using animal models of cardiac tamponade, designed to prevent atrial stretch during increases in atrial pressure, implied that the increase in atrial transmural pressure with associated atrial stretch acts as the principal mediator controlling the acute release of ANP. ${ }^{16,17}$ 
RELATIUE ANP PLASMA LEUELS AT DIFFERENT PACING MODES AND RATES

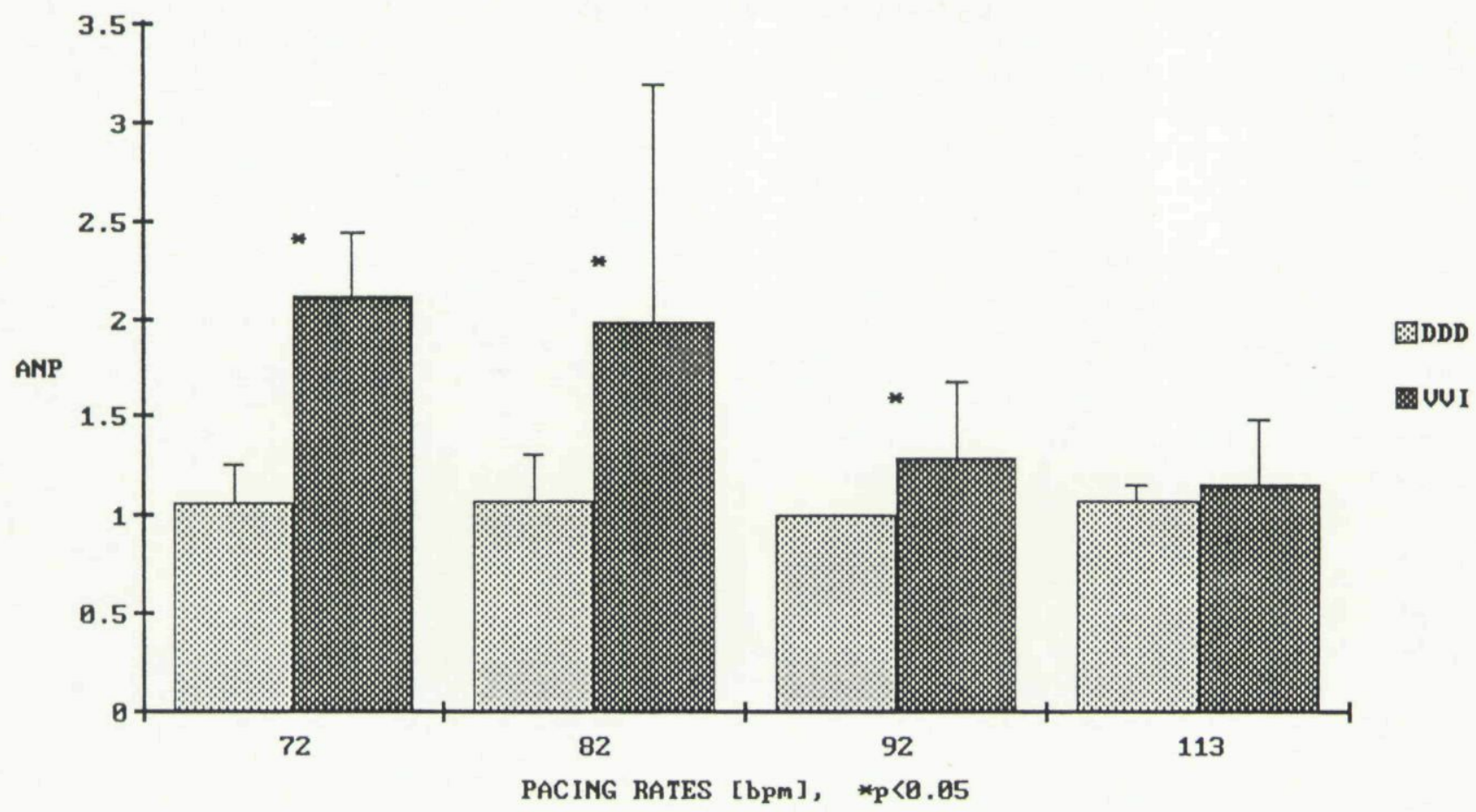

Figure 2. Mean relative ANP plasma levels during DDD and VVI pacing at 72, 82, 92, and 113 beats/min (given are means $\pm \mathrm{SD}$ ).

At body rest, the share of atrial contraction is reported to be approximately $10 \%-20 \%{ }^{7,18-21}$ At increasing heart rates, atrial contribution to cardiac output seems to depend on ventricular function. ${ }^{22,23}$ In patients without impaired myocardial function the atrial contribution to cardiac output seems to decrease at higher pacing rates. Samet and co-workers described that atrioventricular synchrony led to less pronounced increases in cardiac index at higher pacing rates compared to asynchronous pacing at rest. ${ }^{7}$

Karlöf demonstrated similar effects of AV sequential versus single chamber pacing in patients with complete heart block at rest and during exercise. $^{8}$

Obviously, the atrial contribution seems to decrease at higher pacing rates in normal subjects. This might explain observations of only low differences in cardiac output during physical work in patients under DDD stimulation, compared to VVI rate responsive pacing. ${ }^{21}$

Enhanced cardiac output due to exercise or acute increment of pacing rate augments venous return resulting in elevation of atrial filling and mean pulmonary capillary wedge pressure (PCW) ${ }^{24,25}$ Augmented PCW influences atrial contribution to cardiac output. Greenberg and co-workers found that atrial contribution tends to become less effective in elevating stroke volume when PCW increases. ${ }^{26}$ As atrial contribution seems to decrease at higher pacing rates in patients with normal cardiac function, left ventricular preload or PCW becomes more important in the determination of cardiac output. PCW correlates with mean left atrial pressure. ${ }^{25,27}$ As plasma levels of ANP correlate closely to atrial pressure and tension, ${ }^{14-17}$ it can be expected that differences in ANP plasma levels between DDD and VVI pacing decline as pacing rate increases in patients without impaired myocardial function.

These theoretical considerations are supported by our present study. While the relative ANP plasma concentrations were twofold higher at 72 and 82 beats/min in VVI compared to DDD 
pacing, the differences between the two pacemaker stimulation modes at 92 beats/min were less pronounced and only differed by a factor of 1.3. At 113 beats/min both relative and absolute hormone levels were nearly identical, which might represent a negligible atrial contribution to cardiac output at this pacing rate. Furthermore, this might explain, why a minimum in ANP plasma levels at a certain AV delay under DDD mode at 113 beats/min was not found, whereas such a minimum was detectable at a lower pacing rate as we described earlier. ${ }^{6}$

To fully corroborate our findings, it would be necessary to evaluate ventricular volumes during atrial pacing in order to precisely document the differences in atrial contribution to cardiac output. ${ }^{23}$ However, this was not possible in the outpatients examined in our study. Our data demonstrate that measurements of plasma ANP is a useful method which should supplement invasive diagnostic approaches in detecting hemodynamic changes under pacemaker stimulation.

Acknowledgment: The data were presented at the 11th annual scientific session of the North American Society of Pacing and Electrophysiology, 1990, in San Diego, California, and have appeared in abstract form (PACE 1990; 13:559). B. Göke is a research fellow of the Deutsche Forschungsgemeinschaft (DFG: Heisenberg program). We are grateful to I. Muttschall for skillful technical assistance.

\section{References}

1. Needleman P, Greenwald JE. Atriopeptin: A cardiac hormone involved in fluid, electrolyte, and blood-pressure homeostasis. N Engl J Med 1986; 314:828-834.

2. Lang RE, Thölken H, Ganten D, et al. Atrial natriuretic factor-a circulating hormone stimulated by volume loading. Nature 1985; 314:264-266.

3. Crozier IG, Nicholls MG, Ikram H, et al. Relation between left atrial diameter and plasma atrial natriuretic peptide, renin and vasopressin. Am J Cardiol 1986; 58:1134-1136.

4. Haufe MC, Weil J, Nafzger K, et al. Acute increase in right atrial pressure by intracardiac stimulation releases atrial natriuretic peptide. Eur Heart J 1987; 8:277-281.

5. Stangl K, Weil J, Seitz K, et al. Influence of AV synchrony on the plasma levels of atrial natriuretic peptide (ANP) in patients with total AV block. PACE 1987; 11:1176-1181.

6. Noll B, Krappe J, Göke B, et al. Influence of pacing mode and rate on peripheral levels of atrial natriuretic peptide (ANP). PACE 1989; 12:17631768.

7. Samet P, Castillo C, Bernstein WH. Hemodynamic consequences of atrial and ventricular pacing in subjects with normal hearts. Am J Cardiol 1966; 18:522-525.

8. Karlöf J. Haemodynamic effect of atrial triggered versus fixed rate pacing at rest and during exercise in complete heart block. Acta Med Scand 1975; 197:195-206.

9. Fananapazir L, Bennett DH, Monks P. Atrial synchronized ventricular pacing: Contribution of the chronotropic response to improved exercise performance. PACE 1983; 6:601-608.

10. Riegger GAJ, Elsner D, Kromer EP, et al. Atrial natriuretic peptide in congestive heart failure in

the dog: Plasma levels, cyclic guanosine monophosphate, ultrastructure of atrial myoendocrine cells, and hemodynamic, hormonal, and renal effects. Circulation 1988; 77(2):398-406.

11. Goetz KL. Physiology and pathophysiology of atrial peptides. Am J Physiol 1988; 254:E1-E15.

12. Kadowitz PJ, Needleman P, Hyman AL. Vasodilator actions of atriopeptin II in the feline pulmonary vascular bed (abstract). Circulation 1984; 70 (Suppl. II):34.

13. Haufe MC, Weil J, Gerzer R, et al. Effects of repeated increments in right atrial pressure on secretion of atrial natriuretic factor. Am J Cardiol 1988, 61:932-934.

14. Ellenbogen KA, Rogers R, Walsh M, et al. Increased circulating atrial natriuretic factor (ANF) release during induced ventricular tachycardia. Am Heart J 1988; 116:1233-1238.

15. Ellenbogen KA, Mohanty PK, Sowers JR, et al. Atrial natriuretic factor release is enhanced by incremental atrial pacing. Am Heart J 1988; 116:489-496.

16. Mancini GBJ, McGillem MJ, Bates ER, et al. Hormonal responses to cardiac tamponade: Inhibition of release of atrial natriuretic factor despite elevation of atrial pressures. Circulation 1987; 76:884890.

17. Edwards BS, Zimmermann RS, Schwab TR, et al. Atrial stretch, not pressure, is the principal determinant controlling the acute release of atrial natriuretic factor. Circ Res 1988; 62:191-195.

18. Samet P, Castillo C, Bernstein WH. Hemodynamic sequelae of atrial, ventricular, and sequential atrioventricular pacing in cardiac patients. Am Heart J 1966; 72(6):725-729.

19. Braunwald E. Symposium on cardiac arrhythmias. Introduction. With comments on the hemo- 
dynamic significance of atrial systole. Am J Med 1964; 37:665-669.

20. Gilmore JP, Sarnoff SJ, Mitchell JH, et al, Synchronicity of ventricular contraction: Observations comparing hemodynamic effects of atrial and ventricular pacing. Br Heart J 1963; 25:299307.

21. Maisch B. Physiologische Stimulation-Möglichkeiten und Probleme. In B Maisch, H Steilner (eds.): Praktische Herzschrittmachertherapie. Erlangen: perimed Fachbuch-Verlagsgesellschaft, 1985, pp. 61-79.

22. Reiter MJ, Hindman MC. Hemodynamic effects of acute atrioventricular sequential pacing in patients with left ventricular dysfunction. Am J Cardiol 1982; 49:687-692.

23. Hamer AW, Zahner CA, Rubin SA, et al. Hemodynamic benefits of synchronized 1:1 atrial pacing during sustained ventricular tachycardia with severely depressed ventricular function in coronary heart disease. Am J Cardiol 1985; 55:990-994.

24. Braunwald E, Sonnenblick EH, Ross J. Mechanisms of cardiac contraction and relaxation. In E Braunwald (ed.): Heart Disease. Philadelphia, WB Saunders, 1988, pp. 383-425.

25. Görnandt L. Rechtsherzeinschwemmkatheteruntersuchung. In $\mathrm{H}$ Roskamm, $\mathrm{H}$ Reindell (eds.): Herzkrankheiten. New York, Springer, 1989, pp. 322-328.

26. Greenberg B, Chatterjee K, Parmley WW, et al. The influence of left ventricular filling pressure on atrial contribution to cardiac output. Am Heart J 1979; 98:742-751.

27. Grossman W, Barry WH. Cardiac catheterization. In E Braunwald (ed.): Heart Disease. Philadelphia, WB Saunders, 1988, pp. 242-267. 
This document is a scanned copy of a printed document. No warranty is given about the accuracy of the copy. Users should refer to the original published version of the material. 